\title{
The Total Irregularity of some Composite Graphs
}

\author{
Hosam Abdo \\ Institut für Informatik, Freie Universität Berlin \\ Takustraße 9, D-14195 Berlin \\ Germany
}

\author{
Darko Dimitrov \\ Hochschule für Technik und Wirtschaft Berlin \\ Wilhelminenhofstraße 75A, D-12459 Berlin \\ Germany
}

\begin{abstract}
The total irregularity of a simple undirected graph $G=(V, E)$ is defined as $\operatorname{irr}_{t}(G)=\frac{1}{2} \sum_{u, v \in V(G)}\left|d_{G}(u)-d_{G}(v)\right|$, where $d_{G}(u)$ is the degree of the vertex $u$. In this paper we investigate the change of the total irregularity of graphs under various subdivision operations. Also, we present exact expressions and upper bounds on the total irregularity of different composite graphs such as the double graph, the extended double cover of a graph, the generalized thorn graph, several variants of subdivision corona graphs, and the hierarchical product graphs.
\end{abstract}

\section{Keywords}

irregularity of a graph, total irregularity of a graph, graph invariants, composite graphs

\section{INTRODUCTION}

In this paper, all graphs are simple and connected. Let $G=(V, E)$ be a graph with $n$ vertices and $m$ edges. We denote the degree of a vertex $u$ by $d_{G}(u)$ and the maximum and minimum degree of the graph $G$ by $\Delta$ and $\delta$, respectively. The imbalance of an edge $e=(u, v) \in E(G)$ is defined as $i m b(e)=\left|d_{G}(u)-d_{G}(v)\right|$. In [4], Albertson defined the irregularity of $G$ as

$$
\operatorname{irr}(G)=\sum_{e \in E(G)} \operatorname{imb}(e)=\sum_{(u, v) \in E(G)}\left|d_{G}(u)-d_{G}(v)\right|
$$

and found upper bounds of irregularity for bipartite graphs, triangle-free graphs and a sharp upper bound of irregularity for trees. Hansen and Mélot [15] characterized the graphs with $n$ vertices and $m$ edges with maximal irregularity.

Recently in [1] a new measure of irregularity of a graph, so-called the total irregularity, that depends also on one single parameter (the pairwise difference of vertex degrees) was introduced. It was defined as

$$
\operatorname{irr}_{t}(G)=\frac{1}{2} \sum_{u, v \in V(G)}\left|d_{G}(u)-d_{G}(v)\right| .
$$

In this paper, we assume that for a graph $G$ with the vertex set $V(G)=\left\{v_{1}, v_{2}, \ldots, v_{n}\right\}$ the order $d\left(v_{1}\right) \geq d\left(v_{2}\right) \geq \ldots \geq d\left(v_{n}\right)$ holds. Then,

$$
\operatorname{irr}_{t}(G)=\sum_{i<j}\left(d\left(v_{i}\right)-d\left(v_{j}\right)\right)=\sum_{i=1}^{n-1} \sum_{j=i+1}^{n}\left(d\left(v_{i}\right)-d\left(v_{j}\right)\right) .
$$

The motivation to introduce the total irregularity of a graph, as modification of the irregularity of graph, is twofold [1]. First, in contrast to $\operatorname{irr}(G), \operatorname{irr}_{t}(G)$ can be computed directly from the sequence of the vertex degrees (degree sequence) of $G$. Second, the most irregular graphs with respect to irr are graphs that have only two degrees. On the contrary the most irregular graphs with respect to $\operatorname{irr}_{t}$, as it is shown in [1], are graphs with maximal number of different vertex degrees, which is much closer to what one can expect from "very" irregular graphs. Also in [1], sharp upper bounds on the total irregularity of a graph were given. Recently, irregularity measures irr and irr $_{t}$ were compared in [13], where it was shown that for a connected graph $G$ with $n$ vertices $\operatorname{irr}_{t}(G) \leq n^{2} \operatorname{irr}(G) / 4$. Moreover, if $G$ is a tree, then it was shown that $\operatorname{irr}_{t}(G) \leq(n-2) \operatorname{irr}(G)$. A lot of researches on irregularity of graphs have been carried out recently [2 3, 7]. In this work we investigate the change of the total irregularity under different graph operations. The rest of the paper is structured as follows. In Sections 2 exact expressions of the total irregularity of graphs under several graph subdivision operations are presented. Exact expressions of the total irregularity for double graphs and extended double cover graphs are given in Section 3 The sharp upper bound on the total irregularity of thorn graphs is presented in Section 4 while in Sections 5 and 6 exact expressions and upper bounds on the total irregularity of several subdvision corona graphs and hierarchical product graphs are given.

\section{TOTAL IRREGULARITY OF SOME SUBDIVISION GRAPHS}

DEFINITION 1. The line graph of $G$, denoted by $L(G)$ is the graph whose vertices are the edges of $G$ and two vertices of $L(G)$ are adjacent if and only if the corresponding edges are adjacent in G.

Next, we presented definitions of several subdivision graphs whose the total irregularities will be studied in this section.

DEFINITION 2. The subdivision graph of a graph $G$ denoted by $S(G)$ is obtained from $G$ by replacing each edge of $G$ by a path of length two.

DEFINITION 3. The triangle parallel graph of a graph $G$ is denoted by $R(G)$ and is obtained from $G$ by replacing each edge of $G$ by a triangle.

DEFINITION 4. The line superposition graph $Q(G)$ of a graph $G$ is obtained from $G$ by inserting a new vertex into each edge of 
$G$, and joining with edges each pair of new vertices on adjacent edges of $G$.

DEFINITION 5. The total graph $T(G)$ of a graph $G$ has a vertex for each edge and vertex of $G$, and two vertces in $T(G)$ are adjacent if and only if their corresponding elements are either adjacent or incident in $G$.

DEFINITION 6. A sequence $D=\left[d_{1}, d_{2}, \ldots, d_{n}\right]$ is graphical if there is a graph whose vertex degrees are $d_{i}, i=1, \ldots, n$. If in addition $d_{1} \geq d_{2} \geq \cdots \geq d_{n}$, then $D$ is a degree sequence. Furthermore, the notation $D(G)=\left[x_{1}^{n_{1}}, x_{2}^{n_{2}}, \cdots, x_{t}^{n_{t}}\right]$ means that the degree sequence is comprised of $n_{i}$ vertices of degree $x_{i}$, where $i=1,2, \cdots, t$.

First, we determine the total irregularity of the subdivision graph $S(G)$ and the line graph $L(G)$ of $G$ in terms of the number of vertices, edges, and the total irregularity of $G$.

THEOREM 7. Let $G$ be simple undirected connected graphs with $|V(G)|=n,|E(G)|=m$ and $r$ pendent vertices. Then,

$$
\operatorname{irr}_{t}(S(G))=\operatorname{irr}_{t}(G)+2 m(m+r-n) .
$$

Proof. Since $S(G)$ is obtained from $G$ by replacing each edge by a path of length two, it follows that $|V(S(G))|=n+m$ and $|E(S(G))|=2 m$. Also, $d_{S(G)}(v)=d_{G}(v)$, if $v \in V(G)$, otherwise $d_{S(G)}(v)=2$. Consider the degree sequence of $V(G)=$ $\left\{v_{1}, v_{2}, \ldots, v_{n}\right\}$ with $d\left(v_{1}\right) \geq d\left(v_{2}\right) \geq \ldots \geq d\left(v_{n-r}\right)>$ $\underbrace{1=\ldots=1}_{r \text {-times }}$. Then, $V(S(G))=\{v_{1}, v_{2}, \ldots, v_{n}, \underbrace{2, \ldots, 2}_{m-\text { times }}\}$ with $d\left(v_{1}\right) \geq d\left(v_{2}\right) \geq \ldots \geq d\left(v_{n-r}\right) \geq \underbrace{2=\ldots=2}_{m \text {-times }}>\underbrace{1=\ldots=1}_{r \text {-times }}$, and the total irregularity of $G$ is

$$
\begin{aligned}
\operatorname{ir}_{t}(G)=\frac{1}{2} \sum_{u, v \in V(G)}\left|d_{G}(u)-d_{G}(v)\right| \\
=\sum_{i=1}^{n-1} \sum_{j=i+1}^{n}\left(d_{G}\left(v_{i}\right)-d_{G}\left(v_{j}\right)\right) \\
=\sum_{i=1}^{n-r} \sum_{j=i+1}^{n-r}\left(d_{G}\left(v_{i}\right)-d_{G}\left(v_{j}\right)\right)+\sum_{i=1}^{n-r} \sum_{j=n-r+1}^{n}\left(d_{G}\left(v_{i}\right)-1\right) \\
=\sum_{i=1}^{n-r} \sum_{j=i+1}^{n-r}\left(d_{G}\left(v_{i}\right)-d_{G}\left(v_{j}\right)\right)+\sum_{i=1}^{n-r}\left(d_{G}\left(v_{i}\right)-1\right)(n-n+r) \\
=\sum_{i=1}^{n-r} \sum_{j=i+1}^{n-r}\left(d_{G}\left(v_{i}\right)-d_{G}\left(v_{j}\right)\right)+r \sum_{i=1}^{n-r} d_{G}\left(v_{i}\right)-r(n-r) \\
=\sum_{i=1}^{n-r} \sum_{j=i+1}^{n-r}\left(d_{G}\left(v_{i}\right)-d_{G}\left(v_{j}\right)\right)+r(2 m-r-n+r) \\
=\sum_{i=1}^{n-r} \sum_{j=i+1}^{n-r}\left(d_{G}\left(v_{i}\right)-d_{G}\left(v_{j}\right)\right)+r(2 m-n),
\end{aligned}
$$

and the total irregularity of $S(G)$ is

$$
\begin{aligned}
& \operatorname{ir}_{t}(S(G))=\frac{1}{2} \sum_{u, v \in V(S(G))}\left|d_{S(G)}(u)-d_{S(G)}(v)\right| \\
& =\sum_{i=1}^{n-1} \sum_{j=i+1}^{n}\left(d_{S(G)}\left(v_{i}\right)-d_{S(G)}\left(v_{j}\right)\right)
\end{aligned}
$$

$$
\begin{aligned}
= & \sum_{i=1}^{n-r} \sum_{j=i+1}^{n-r}\left(d_{S(G)}\left(v_{i}\right)-d_{S(G)}\left(v_{j}\right)\right)+ \\
& \sum_{i=1}^{n-r} \sum_{j=n-r+1}^{n-r+m}\left(d_{S(G)}\left(v_{i}\right)-2\right)+ \\
& \sum_{i=1}^{n-r} \sum_{j=n-r+m+1}^{n+m}\left(d_{S(G)}\left(v_{i}\right)-1\right)+\sum_{i=n-r+1}^{n-r+m} \sum_{j=n-r+m+1}^{n+m} 1 \\
= & \sum_{i=1}^{n-r} \sum_{j=i+1}^{n-r}\left(d_{G}\left(v_{i}\right)-d_{G}\left(v_{j}\right)\right)+ \\
& \left.\sum_{i=1}^{n-r}\left[d_{G}\left(v_{i}\right)(m+r)-2 m-r\right)\right]+m r \\
= & \sum_{i=1}^{n-r} \sum_{j=i+1}^{n-r}\left(d_{G}\left(v_{i}\right)-d_{G}\left(v_{j}\right)\right)+(2 m-r)(m+r)- \\
& (2 m+r)(n-r)+m r \\
= & \sum_{i=1}^{n-r} \sum_{j=i+1}^{n-r}\left(d_{G}\left(v_{i}\right)-d_{G}\left(v_{j}\right)\right)+r(2 m-n)+2 m(m+r-n)
\end{aligned}
$$

From (4) and (5), we obtain $\operatorname{irr}_{t}(S(G))=\operatorname{irr}_{t}(G)+2 m(m+r-n)$.

Next, we determine the total irregularity of the line graph. Let $G=$ $(E, V)$ be a graph with $|V(G)|=n,|E(G)|=m$. Then $L(G)$ satisfies $|V(L(G))|=m,|E(L(G))|=\sum_{v \in V(G)} d_{G}(v)^{2}-m$. It follows that $d_{L(G)} e_{i}=d_{G}\left(u_{i}\right)+d_{G}\left(v_{i}\right)-2$ for all $e_{i}=u_{i} v_{i} \in$ $L(G)$.

Proposition 1. Let $L(G)$ be the line graph of $G$. Then, $\operatorname{irr}_{t}(L(G)) \leq 2 \operatorname{irr}_{t}(G)$. The bound is sharp.

Proof. Since $d_{L(G)} e_{i}=d_{G}\left(u_{i}\right)+d_{G}\left(v_{i}\right)-2$. Then

$$
\begin{aligned}
& \operatorname{ir}_{t}(L(G))=\frac{1}{2} \sum_{e_{i}, e_{j} \in V(L(G))}\left|d_{L(G)}\left(e_{i}\right)-d_{L(G)}\left(e_{j}\right)\right| \\
&=\frac{1}{2} \sum_{u_{i} u_{j}, v_{i} v_{j} \in E(G)} \mid\left(d_{G}\left(u_{i}\right)+d_{G}\left(v_{i}\right)-2\right)- \\
&=\frac{1}{2} \sum_{u_{i} v_{i}, u_{j} v_{j} \in E(G)}\left|\left(d_{G}\left(u_{i}\right)-d_{G}\left(v_{j}\right)-2\right)\right| \\
& \leq \frac{1}{2} \sum_{u_{i}, v_{i} \in V(L(G))}\left|d_{G}\left(u_{i}\right)-d_{G}\left(v_{i}\right)\right|+ \\
&\left.\frac{1}{2} \sum_{u_{j}, v_{j} \in V(L(G))} \mid d_{G}\left(u_{j}\right)-d_{G}\left(v_{j}\right)\right) \mid \\
&= 2 \operatorname{irr}_{t}(G)
\end{aligned}
$$

To show the bound is sharp, consider the complete graph $K_{n}$. The line graph $L\left(K_{n}\right)$ is the $(2 n-4)$-regular graph of order $\left(\begin{array}{l}n \\ 2\end{array}\right)$. Then $\mathrm{D}\left(\mathrm{K}_{\mathrm{n}}\right)=\left[(\mathrm{n}-1)^{\mathrm{n}}\right]$ and $\mathrm{D}\left(\mathrm{L}\left(\mathrm{K}_{\mathrm{n}}\right)\right)=\left[(2 \mathrm{n}-4)^{\frac{\mathrm{n}(\mathrm{n}-1)}{2}}\right]$. Hence, $\operatorname{irr}_{t}\left(K_{n}\right)=\operatorname{irr}_{t}\left(L\left(K_{n}\right)\right)=0$.

Next, we determine the total irregularity of the triangle parallel graph. 
THEOREM 8. The total irregularity of the triangle parallel graph $R(G)$ of a graph $G$ is

$$
\operatorname{irr}_{t}(R(G))=2 \operatorname{irr}_{t}(G)+2 m(2 m-n) .
$$

Proof. From the definition of the triangle parallel graph $R(G)$ of $G$, one can conclude that $|V(R(G))|=n+m$ and $|E(R(G))|=3 m$. Also, it follows that $d_{R(G)}(v)=2 d_{G}(v)$, if $v \in V(G)$, and $d_{R(G)}(v)=2$, if $v \in V(R(G)) \backslash V(G)$. Hence, from (3) the total irregularity of $R(G)$ is

$$
\begin{aligned}
& \operatorname{ir}_{t}(R(G))=\sum_{i=1}^{n+m-1} \sum_{j=i+1}^{n+m}\left(d_{R(G)}\left(v_{i}\right)-d_{R(G)}\left(v_{j}\right)\right) \\
& =\sum_{i=1}^{n}\left(\sum_{j=i+1}^{n}\left(d_{R(G)}\left(v_{i}\right)-d_{S(G)}\left(v_{j}\right)\right)+\sum_{j=n+1}^{n+m}\left(d_{S(G)}\left(v_{i}\right)-2\right)\right) \\
& =\sum_{i=1}^{n} \sum_{j=i+1}^{n}\left(2 d_{G}\left(v_{i}\right)-2 d_{G}\left(v_{j}\right)\right)+\sum_{i=1}^{n} \sum_{j=n+1}^{n+m}\left(2 d_{G}\left(v_{i}\right)-2\right) \\
& =2 \sum_{i=1}^{n} \sum_{j=i+1}^{n}\left(d_{G}\left(v_{i}\right)-d_{G}\left(v_{j}\right)\right)+2 m \sum_{i=1}^{n}\left(d_{G}\left(v_{i}\right)-1\right) \\
& =2 \operatorname{irr}_{t}(G)+2 m(2 m-n) .
\end{aligned}
$$

Now, we determine the total irregularity of the line superposition graph $Q(G)$ in terms of the total irregularities of the graph $G$ and its line graph $L(G)$.

THEOREM 9. The total irregularity of the line superposition graph $Q(G)$ of $G$ is

$$
\begin{aligned}
\operatorname{irr}_{t}(Q(G))= & \operatorname{irr}_{t}(G)+\operatorname{irr}_{t}(L(G))+ \\
& \frac{1}{2} \sum_{\substack{t \in V(L(G)) \\
z \in V(G)}}\left|d_{L(G)}(t)-d_{G}(z)+2\right|
\end{aligned}
$$

PROOF. From the construction of $Q(G)$, we obtain that $|V(Q(G))|=n+m$ and $|E(Q(G))|=2 m+|E(L(G))|$. Also, $d_{Q(G)}(v)=d_{G}(v)$, if $v \in V(G)$, and $d_{R(G)}(v)=d_{L(G)}(v)+$ 2 , if $v \in V(R(G)) \backslash V(G)$. Hence, from [2, the total irregularity of $Q(G)$ is

$$
\begin{aligned}
\operatorname{ir}_{t}(Q(G))=\frac{1}{2} \sum_{u, v \in V(Q(G))}\left|d_{Q(G)}(u)-d_{Q(G)}(v)\right| \\
=\frac{1}{2} \sum_{u, v \in V(Q(G)) \backslash V(G)}\left|d_{Q(G)}(u)-d_{Q(G)}(v)\right|+ \\
\quad \frac{1}{2} \sum_{p, q \in V(G)}\left|d_{Q(G)}(p)-d_{Q(G)}(q)\right|+ \\
\quad \frac{1}{2} \sum_{t \in V(Q(G)) \backslash V(G)}\left|d_{Q(G)}(t)-d_{Q(G)}(z)\right| \\
\left.=\frac{1}{2} \sum_{u, v \in V(G)} \mid d_{L(G)}(u)+2\right)-\left(d_{L(G)}(v)+2\right) \mid+ \\
\quad \frac{1}{2} \sum_{p, q \in V(G)}\left|d_{G}(p)-d_{G}(q)\right|+
\end{aligned}
$$

$$
\begin{aligned}
& \frac{1}{2} \sum_{\substack{t \in V(L(G)) \\
z \in V(G)}}\left|d_{L(G)}(t)+2-d_{G}(z)\right| \\
= & \operatorname{irr}_{t}(L(G))+\operatorname{irr}_{t}(G)+ \\
& \frac{1}{2} \sum_{\substack{t \in V(L(G)) \\
z \in V(G)}}\left|d_{L(G)}(t)-d_{G}(z)+2\right| .
\end{aligned}
$$

Finally, we present the total irregularity of the total graph $T(G)$ in terms of the total irregularity of graph $G$ and its line graph $L(G)$.

THEOREM 10. The total irregularity of the total graph $T(G)$ of $G$ is

$$
\begin{aligned}
\operatorname{irr}_{t}(T(G))= & 2 \operatorname{irr}_{t}(G)+\operatorname{irr}_{t}(L(G))+ \\
& \frac{1}{2} \sum_{\substack{u \in V(G) \\
v \in V(T(G)) \backslash V(G)}}\left|2 d_{G}(u)-d_{L(G)}(v)-2\right|
\end{aligned}
$$

Proof. From the definition of total graph, it follows that $V(T(G))=V(G) \cup E(G)$. Also from the fact that two vertices of $T(G)$ are adjacent if and only if the corresponding elements of $G$ are either adjacent or incident, one can obtain that $|V(T(G))|=n+m$ and $|E(T(G))|=3 m+|E(L(G))|$. Also, it follows that $d_{T(G)}(v)=2 d_{G}(v)$, if $v \in V(G)$ and $d_{T(G)}(v)=d_{L(G)}(v)+2$, if $v \in V(T(G)) \backslash V(G)$. Therefore, the total irregularity of the total graph $T(G)$ is

$$
\begin{aligned}
\operatorname{irr}_{t}(T(G))=\frac{1}{2} \sum_{u, v \in V(T(G))}\left|d_{T(G)}(u)-d_{T(G)}(v)\right| \\
=\frac{1}{2} \sum_{u, v \in V(G)}\left|d_{T(G)}(u)-d_{T(G)}(v)\right|+ \\
\quad \frac{1}{2} \sum_{u, v \in V(T(G)) \backslash V(G)}\left|d_{T(G)}(u)-d_{T(G)}(v)\right|+ \\
\quad \frac{1}{2} \sum_{\substack{u \in V(G) \\
v \in V(T(G)) \backslash V(G)}}\left|d_{T(G)}(u)-d_{T(G)}(v)\right| \\
\quad \sum_{\substack{u, v \in V(G)\\
}}\left|2 d_{G}(u)-2 d_{G}(v)\right|+ \\
\quad \sum_{u, v \in V(L(G))}\left|d_{L(G)}(u)+2-d_{L(G)}(v)-2\right|+ \\
=\frac{1}{2} \sum_{\substack{u \in V(G) \\
v \in V(T(G)) \backslash V(G)}}\left|2 d_{G}(u)-d_{L(G)}(v)-2\right| \\
\frac{1}{2} \sum_{\substack{u \in V(G) \\
v \in V(T(G)) \backslash V(G)}}\left|2 d_{G}(u)-d_{L(G)}(v)-2\right| .
\end{aligned}
$$

EXAMPLE 1. Let $K_{a, b}$ be the complete bipartite graph where $a, b \geq 2$ and $P_{n}$ be a path on $n$ vertices $(n \geq 2)$. The following results are obtained directly from Theorems $7,8,8,9$ and 10.

(1) $\operatorname{irr}_{t}\left(S\left(K_{a, b}\right)\right)=a b(2 a b-a-b)$ 


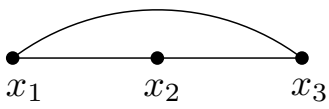

(a)

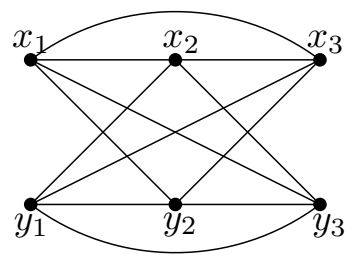

(b)

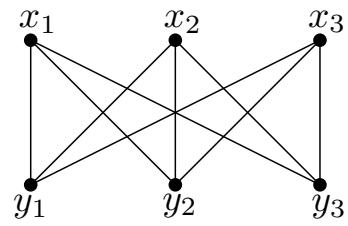

(c)

Fig. 1. (a) Cycle graph $C_{3}$, (b) Double graph $C_{3}^{*}$, (c) Extended double cover $C_{3}^{* *}$.

(2) $\operatorname{irr}_{t}\left(R\left(P_{n}\right)\right)=2(n+1)(n-2)$

(3) $\operatorname{irr}_{t}\left(Q\left(P_{n}\right)\right)=2(n+3)(n-2)$

(4) $\operatorname{irr}_{t}\left(T\left(P_{n}\right)\right)=2(6 n-13)$

\section{TOTAL IRREGULARITY OF DOUBLE GRAPH AND EXTENDED DOUBLE COVER}

In this section, we give exact expressions of the total irregularity of double graph and extended double cover [5, 12, 17].

DEFINITION 11. The double graph $G^{*}$ of a given graph $G$ is constructed by making two copies of $G$ (including the initial edge set of each) and adding edges $u_{1} v_{2}$ and $v_{1} u_{2}$ for every edge uv of $G$.

DEFINITION 12. The extended double cover of $G$, denoted by $G^{* *}$ is the bipartite graph with bipartition $(X, Y)$ where $X=$ $\left\{x_{1}, x_{2}, \ldots, x_{n}\right\}$ and $Y=\left\{y_{1}, y_{2}, \ldots, y_{n}\right\}$ in which $x_{i}$ and $y_{j}$ are adjacent if and only if either $v_{i}$ and $v_{j}$ are adjacent in $G$ or $i=j$.

For example, the extended double cover graph of the complete graph is the complete bipartite graph. This construction of the extended double cover graph was introduced by Alon [5]. The double graph $C_{3}^{*}$ and the extended double cover graph $C_{3}^{* *}$ of the cycle $C_{3}$ are illustrated respectively in Figure 1

THEOREM 13. The total irregularity of the double graph $G^{*}$ and the total irregularity of the extended double cover $G^{* *}$ of the graph $G$ are

$$
\operatorname{irr}_{t}\left(G^{*}\right)=8 \operatorname{irr}_{t}(G), \quad \operatorname{irr}_{t}\left(G^{* *}\right)=4 \operatorname{irr}_{t}(G) .
$$

PROOF. From the definition of double graph, we one can obtain that $d_{G^{*}}\left(x_{i}\right)=d_{G^{*}}\left(y_{i}\right)=2 d_{G}\left(v_{i}\right)$, where $v_{i} \in V(G)$ and $x_{i}, y_{i} \in V\left(G^{*}\right)$ are corresponding clone vertices of $v_{i}$. Thus the total irregularity of double graph $G^{*}$ is

$$
\operatorname{irr}_{t}\left(G^{*}\right)=\frac{1}{2} \sum_{u, v \in V\left(G^{*}\right)}\left|d_{G^{*}}(u)-d_{G^{*}}(v)\right|
$$

$$
\begin{aligned}
= & \frac{1}{2} \sum_{x_{i}, x_{j} \in X}\left|2 d_{G}\left(x_{i}\right)-2 d_{G}\left(x_{j}\right)\right|+ \\
& \frac{1}{2} \sum_{y_{i}, y_{j} \in Y}\left|2 d_{G}\left(y_{i}\right)-2 d_{G}\left(y_{j}\right)\right|+ \\
& \sum_{x_{i}, \in X, y_{j} \in Y}\left|2 d_{G}\left(x_{i}\right)-2 d_{G}\left(y_{j}\right)\right| \\
= & 8 \operatorname{irr}_{t}(G)
\end{aligned}
$$

By definition of the extended double cover $G^{* *}$, one can conclude that $G^{* *}$ consists of $2 n$ vertices, $(n+2 m)$ edges and $d_{G^{* *}}\left(x_{i}\right)=$ $d_{G^{* *}}\left(y_{i}\right)=d_{G}\left(v_{i}\right)+1$ for $i=1,2, \ldots, n$. Here, $v_{i} \in V(G)$ and $x_{i}, y_{i} \in V\left(G^{* *}\right)$ are corresponding clone vertices of $v_{i}$. Thus the total irregularity of extended double cover $G^{* *}$ is

$$
\begin{aligned}
\operatorname{irr}_{t}\left(G^{* *}\right)= & \frac{1}{2} \sum_{u, v \in V\left(G^{* *}\right)}\left|d_{G^{* *}}(u)-d_{G^{* *}}(v)\right| \\
= & \frac{1}{2} \sum_{x_{i}, x_{j} \in X}\left|d_{G}\left(x_{i}\right)+1-d_{G}\left(x_{j}\right)-1\right|+ \\
& \frac{1}{2} \sum_{y_{i}, y_{j} \in Y}\left|d_{G}\left(y_{i}\right)+1-d_{G}\left(y_{j}\right)-1\right|+ \\
& \sum_{x_{i}, \in X, y_{j} \in Y}\left|d_{G}\left(x_{i}\right)+1-d_{G}\left(y_{j}\right)-1\right| \\
= & 4 \operatorname{irr}_{t}(G) .
\end{aligned}
$$

\section{TOTAL IRREGULARITY OF THORN GRAPH}

An edge $e=(u, v)$ of a graph $G$ is called a thorn if either $d(u)=1$ or $d(v)=1$. The concept of thorn graph was first introduced by Gutman [14] by joining a number of thorns to each vertex of any given graph $G$. A variety of topological indices of thorn graphs have been recently studied $[8,10,9,11,16,18,21,22,23]$. Let $V(G)=\left\{v_{1}, v_{2}, \ldots, v_{n}\right\}$ and $V\left(G^{T}\right)=V(G) \cup V_{1} \cup V_{2} \cup \ldots \cup$ $V_{n}$ be the vertex sets of $G$ and its thorn graph $G^{T}$, respectively. The vertex set $V_{i}, i=1, \ldots, n$, is the set of vertices of degree 1 attached to the vertex $v_{i}$ in $G^{T}$. It holds that $V_{i} \cap V_{j}=\emptyset, i \neq j$. Let denote the vertices of the set $V_{i}$ by $v_{i j}$, for $i=1,2, \ldots, n$ and $j=1,2, \ldots, p_{i}$. Thus, $\left|V\left(G^{T}\right)\right|=n+z$ where, $z=\sum_{i=1}^{n} p_{i}$ and the degree of the vertices $v_{i}$ in $G^{T}$ are $d_{G^{T}}\left(v_{i}\right)=d_{G}\left(v_{i}\right)+$ $p_{i}$, for $i=1,2, \ldots, n$. In the following, we first present the total irregularity of the general thorn graph $G^{T}$ and then consider some particular cases.

THEOREM 14. The total irregularity of the thorn graph $G^{T}$ of the graph $G$ with $|V(G)|=n,|E(G)|=m$ and $\sum_{i=1}^{n} p_{i}=z$ is

$$
\operatorname{irr}_{t}\left(G^{T}\right) \leq \operatorname{irr}_{t}(G)+z(z+2 m-n)+\sum_{i=1}^{n-1} \sum_{j=i+1}^{n}\left|p_{i}-p_{j}\right|
$$

Proof. The total irregularity of the thorn graph $G^{T}$ is

$$
\begin{gathered}
\operatorname{irr}_{t}\left(G^{T}\right)=\sum_{i=1}^{n+z-1} \sum_{j=i+1}^{n+z}\left|d_{G^{T}}\left(v_{i}\right)-d_{G^{T}}\left(v_{j}\right)\right| \\
=\sum_{i=1}^{n-1} \sum_{j=i+1}^{n}\left|d_{G}\left(v_{i}\right)+p_{i}-d_{G}\left(v_{j}\right)-p_{j}\right|+
\end{gathered}
$$




$$
\begin{aligned}
& \sum_{i=1}^{n} \sum_{j=n+1}^{n+z}\left|d_{G}\left(v_{i}\right)+p_{i}-1\right| \\
\leq & \sum_{i=1}^{n-1} \sum_{j=i+1}^{n}\left|d_{G}\left(v_{i}\right)-d_{G}\left(v_{j}\right)\right|+\sum_{i=1}^{n-1} \sum_{j=i+1}^{n}\left|p_{i}-p_{j}\right|+ \\
& \sum_{i=1}^{n}\left(d_{G}\left(v_{i}\right)+p_{i}-1\right) z \\
= & \operatorname{irr}_{t}(G)+z(z+2 m-n)+\sum_{i=1}^{n-1} \sum_{j=i+1}^{n}\left|p_{i}-p_{j}\right| .
\end{aligned}
$$

Moreover, the bound is sharp and can be obtained for infinitely many graphs.

The following corollaries are direct consequences of the previous theorem.

COROLLARY 4.1. Let $G^{T}$ be a thorn graph with parameters $p_{i}=x$ for all $i$, then

$$
\operatorname{irr}_{t}\left(G^{T}\right)=\operatorname{irr}_{t}(G)+n x(2 m+n(x-1)) .
$$

COROLLARY 4.2. If the parameter $p_{i}(\geq 1)$ is equal to the degree of the corresponding vertex $v_{i}$, for all $i$, then

$$
\operatorname{irr}_{t}\left(G^{T}\right)=2 \operatorname{irr}_{t}(G)+2 m(4 m-n) .
$$

COROLlaRY 4.3. If $\lambda$ is an integer such that $\lambda>\Delta$ and if $G^{T}$ is the thorn graph with parameters $p_{i}=\lambda-d_{G}\left(v_{i}\right)$, then

$$
\operatorname{irr}_{t}\left(G^{T}\right)=n(\lambda-1)(n \lambda-2 m)
$$

COROLLARY 4.4. If the number of thorns, i.e., pendant edges attached to any vertex of the parent graph is a linear function of the degree of the corresponding vertex $v_{i}$, i.e., $p_{i}=a d_{G}\left(v_{i}\right)+b$, where $a$ and $b$ are positive numbers, the total irregularity of the thorn graph is

$\operatorname{irr}_{t}\left(G^{T}\right)=(a+1) \operatorname{irr}_{t}(G)+(2 a m+b n)(2(a+1) m+(b-1) n)$

COROLlaRY 4.5. Let $C_{n, x}$ be the thorny ring (having $n$ ring as parent and $(x-2)$ thorns at each vertex) then $\operatorname{irr}_{t}\left(C_{n, x}\right)=$ $n^{2}(x-1)(x-2)$.

COROLlaRY 4.6. Let $P_{n, x}$ be the thorn path (caterpillar) obtained from $P_{n}$ by attaching $x$ pendent vertices at each vertex of $P_{n}$, then we have $\operatorname{irr}_{t}\left(P_{n, x}\right)=n^{2} x^{2}+(n x+2)(n-2)$.

COROLlARY 4.7. Let $S_{n, x}$ be the thorn star obtained from $S_{n}\left(\cong K_{1, n}\right)$ by joining $x$ thorns at each vertex of the parent graph $S_{n}$. Then, $\operatorname{irr}_{t}\left(S_{n, x}\right)=(n+1)^{2} x^{2}+(n+1)(n-1) x+n(n-1)$.

\section{TOTAL IRREGULARITY OF THE SUBDIVISION CORONA GRAPHS}

Next we consider the total irregularity of the subdivision-vertex corona and the subdivision-edge corona graphs, introduced by $\mathrm{Lu}$ and Miao [20] and the total irregularity of the subdivisionvertex neighborhood corona and the subdivision-edge neighborhood corona graphs, introduced by Liu and Lub [19]. Let $\mathcal{S}(G)$ be the subdivision graph of $G$ and let $I(G)$ be the set of inserted vertices to $\mathcal{S}(G)$.
DEFINITION 15. The subdivision-vertex corona of two vertexdisjoint graphs $G_{1}$ and $G_{2}$, denoted by $G_{1} \odot G_{2}$, is the graph obtained from $\mathcal{S}\left(G_{1}\right)$ and $\left|V\left(G_{1}\right)\right|$ copies of $G_{2}$, all vertex-disjoint, by joining the ith vertex of $V\left(G_{1}\right)$ to every vertex in the ith copy of $G_{2}$.

DEFINITION 16. The subdivision-edge corona of two vertexdisjoint graphs $G_{1}$ and $G_{2}$, denoted by $G_{1} \ominus G_{2}$, is the graph obtained from $\mathcal{S}\left(G_{1}\right)$ and $\left|I\left(G_{1}\right)\right|$ copies of $G_{2}$, all vertex-disjoint, by joining the ith vertex of $I\left(G_{1}\right)$ to every vertex in the ith copy of $G_{2}$.

DEFINITION 17. The subdivision-vertex neighborhood corona of $G_{1}$ and $G_{2}$, denoted by $G_{1} \triangleright G_{2}$, is the graph obtained from the subdivision graph $\mathcal{S}\left(G_{1}\right)$ and $\left|V\left(G_{1}\right)\right|$ copies of $G_{2}$, all vertex disjoint, and joining the neighbours of the ith vertex of $V\left(G_{1}\right)$ to every vertex in the ith copy of $G_{2}$.

DEFINITION 18. The subdivision-edge neighborhood corona of $G_{1}$ and $G_{2}$, denoted by $G_{1} \boxminus G_{2}$, is the graph obtained from $\mathcal{S}\left(G_{1}\right)$ and $\left|I\left(G_{1}\right)\right|$ copies of $G_{2}$, all vertex disjoint, and joining the neighbours of the ith vertex of $I\left(G_{1}\right)$ to every vertex in the ith copy of $G_{2}$.

Note that if $G_{1}$ and $G_{2}$ are two graphs on disjoint sets of $n_{1}$ and $n_{2}$ vertices, $m_{1}$ and $m_{2}$ edges, respectively, then $G_{1} \odot G_{2}$ has $n_{1}+n_{1} n_{2}+m_{1}$ vertices, $2 m_{1}+n_{1} m_{2}+n_{1} n_{2}$ edges, $G_{1} \odot G_{2}$, has $n_{1}+m_{1}+m_{1} n_{2}$ vertices, $2 m_{1}+m_{1} m_{2}+m_{1} n_{2}$ edges, $G_{1} \square G_{2}$ has $n_{1}+m_{1}+n_{1} n_{2}$ vertices, $2 m_{1}+n_{1} m_{2}+2 m_{1} n_{2}$ edges, and $G_{1} \boxminus G_{2}$ has $n_{1}+m_{1}+m_{1} n_{2}$ vertices, $2 m_{1}+m_{1} n_{2}+2 m_{1} n_{2}$ edges.

EXAMPLE 2. An illustration of the above presented product corona graphs of the path and the cycle on $n$ vertices is given in Figure 2

THEOREM 19. The total irregularity of the subdivision corona graphs are

(I) $\operatorname{irr}_{t}\left(G_{1} \odot G_{2}\right)=\operatorname{irr}_{t}\left(G_{1}\right)+n_{1} \operatorname{irr}_{t}\left(G_{2}\right)+n_{1}^{2}\left(n_{2}^{2}-n_{2}-\right.$ $\left.2 m_{2}\right)+2 n_{1} m_{1}\left(n_{2}+m_{2}-1\right)+2 m_{1}^{2}$,

(II) $\operatorname{irr}_{t}\left(G_{1} \odot G_{2}\right)=\operatorname{irr}_{t}\left(G_{1}\right)+m_{1}^{2} \operatorname{irr}_{t}\left(G_{2}\right)+$ $m_{1}^{2}\left(n_{2}^{2}+n_{2}-2 m_{2}\right)+m_{1} \sum_{i=1}^{n_{1}}\left|d_{G_{1}}\left(v_{i}\right)-n_{2}-2\right|+$ $\sum_{i=1}^{n_{1}} \sum_{j=n_{1}+1}^{n_{1}+m_{1} n_{2}}\left|d_{G_{1}}\left(v_{i}\right)-d_{G_{2}}\left(v_{j}\right)-1\right|$,

$($ III $) \operatorname{irr}_{t}\left(G_{1} \boxminus G_{2}\right) \leq\left(n_{2}^{2}+n_{2}+1\right) \operatorname{irr}_{t}\left(G_{1}\right)+$ $n_{1}^{2} \operatorname{irr}_{t}\left(G_{2}\right)+2 n_{1}^{2} m_{2}+m_{1} \sum_{i=1}^{n_{1}}\left|d_{G_{1}}\left(v_{i}\right)-2 n_{2}-2\right|+$ $\sum_{i=1}^{n_{1}} \sum_{l=1}^{n_{2}}\left|d_{G_{1}}\left(v_{i}\right)+d_{G_{2}}\left(v_{l}\right)-2 n_{2}-2\right|$,

(IV) $\operatorname{irr}_{t}\left(G_{1} \boxminus G_{2}\right)=\left(n_{2}+1\right) \operatorname{irr}_{t}\left(G_{1}\right)+m_{1}^{2} \operatorname{irr}_{t}\left(G_{2}\right)+$ $2 m_{1}^{2}\left(n_{2}^{2}+2 n_{2}+m_{2}+1\right)-2 n_{1} m_{1}\left(n_{2}+m_{2}+1\right)$.

Proof. (I) The vertex set of the subdivision-vertex corona $G_{1} \odot G_{2}$ can be partitioned into the subsets

(1) $V_{1}=\left\{v_{i} \in V\left(G_{1} \odot G_{2}\right): d_{G_{1} \odot G_{2}}\left(v_{i}\right)=d_{G_{1}}\left(v_{i}\right)+n_{2}\right.$, $\left.i=1,2, \ldots, n_{1}\right\}$

(2) $V_{2}=\left\{v_{i} \in V\left(G_{1} \odot G_{2}\right): d_{G_{1} \odot G_{2}}\left(v_{i}\right)=d_{G_{2}}\left(v_{i}\right)+1\right.$, $\left.i=1,2, \ldots, n_{1} n_{2}\right\}$, and

(3) $V_{3}=\left\{v_{i} \in V\left(G_{1} \odot G_{2}\right): d_{G_{1} \odot G_{2}}\left(v_{i}\right)=2\right.$, $\left.i=1,2, \ldots, m_{1}\right\}$. 


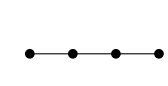

(a)

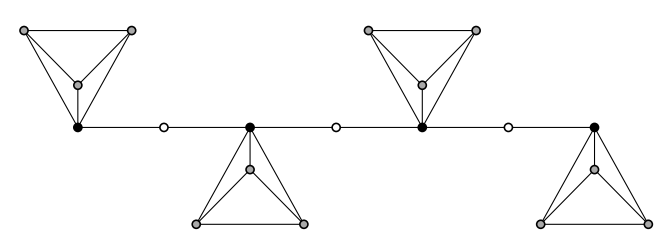

(d)

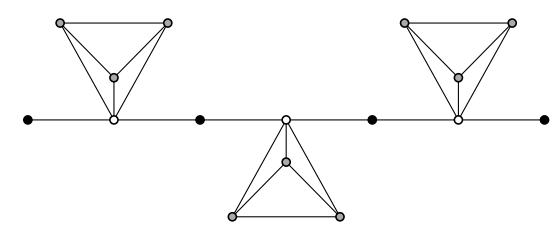

(e)

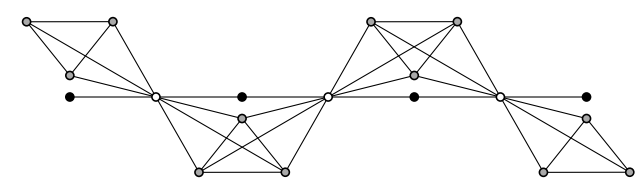

(f)

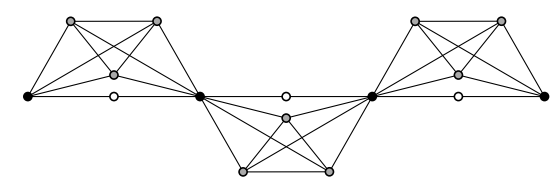

(g)

Fig. 2. (a) Path $P_{4}$, (b) Subdivision $\mathcal{S}\left(P_{4}\right)$, (c) Cycle $C_{3}$, (d) Subdivision-vertex corona $P_{4} \odot C_{3}$, (e) Subdivision-edge corona $P_{4} \odot$ $C_{3}$, (f) Subdivision-vertex neighbourhood corona $P_{4} \square C_{3}$, and (g) Subdivision-edge neighbourhood corona $P_{4} \boxminus C_{3}$ graphs.

Thus, the total irregularity of $G_{1} \odot G_{2}$ is

$$
\begin{aligned}
\operatorname{irr}_{t}\left(G_{1} \odot G_{2}\right)=\sum_{\substack{i=1, j=i+1}}^{\substack{n_{1}+n_{1} n_{2}+m_{1}-1 \\
n_{1}+n_{1} n_{2}+m_{1}}}\left|d_{G_{1} \odot G_{2}}\left(v_{i}\right)-d_{G_{1} \odot G_{2}}\left(v_{j}\right)\right| \\
=\sum_{i=1}^{n_{1}} \sum_{j=i+1}^{n_{1}}\left|d_{G_{1}}\left(v_{i}\right)+n_{2}-d_{G_{1}}\left(v_{j}\right)-n_{2}\right|+ \\
\sum_{i=1}^{n_{1}} \sum_{j=n_{1}+1}^{n_{1}+n_{1} n_{2}}\left|d_{G_{1}}\left(v_{i}\right)+n_{2}-d_{G_{2}}\left(v_{j}\right)-1\right|+ \\
\sum_{i=1}^{n_{1}} \sum_{j=n_{1}+n_{1} n_{2}+1}^{n_{1}+n_{1} n_{2}+m_{1}}\left|d_{G_{1}}\left(v_{i}\right)+n_{2}-2\right|+ \\
\sum_{i=n_{1}+1}^{n_{1}+n_{1} n_{2}} \sum_{j=i+1}^{n_{1}+n_{1} n_{2}}\left|d_{G_{2}}\left(v_{i}\right)+1-d_{G_{2}}\left(v_{j}\right)-1\right|+ \\
\sum_{i=n_{1}+1}^{n_{1}+n_{1} n_{2}} \sum_{j=n_{1}+n_{1} n_{2}+1}^{n_{1}+n_{1} n_{2}+m_{1}}\left|d_{G_{2}}\left(v_{i}\right)+1-2\right|
\end{aligned}
$$

$$
\begin{aligned}
&= \operatorname{irr}_{t}\left(G_{1}\right)+\sum_{i=1}^{n_{1}}\left(n_{1} n_{2}\left(d_{G_{1}}\left(v_{i}\right)+n_{2}-1\right)-2 n_{1} m_{2}+\right. \\
&\left.m_{1}\left(d_{G_{1}}\left(v_{i}\right)+n_{2}-2\right)\right)+n_{1} \operatorname{irr}_{t}\left(G_{2}\right)+ \\
& m_{1} \sum_{i=n_{1}+1}^{n_{1}+n_{1} n_{2}}\left(d_{G_{2}}\left(v_{i}\right)-1\right) \\
&= \operatorname{irr}_{t}\left(G_{1}\right)+n_{1}^{2} n_{2}\left(n_{2}-1\right)-2 n_{1}^{2} m_{2}+2 n_{1} n_{2} m_{1}+2 m_{1}^{2}+ \\
& n_{1} m_{1}\left(n_{2}-2\right)+n_{1} \operatorname{irr}_{t}\left(G_{2}\right)+m_{1} n_{1}\left(2 m_{2}-n_{2}\right) \\
&= \operatorname{irr}_{t}\left(G_{1}\right)+n_{1} \operatorname{irr}_{t}\left(G_{2}\right)+n_{1}^{2}\left(n_{2}^{2}-n_{2}-2 m_{2}\right)+ \\
& 2 n_{1} m_{1}\left(n_{2}+m_{2}-1\right)+2 m_{1}^{2} . \\
& \text { (II) } \operatorname{Let} V\left(G_{1} \ominus G_{2}\right)=V_{1} \cup V_{2} \cup V_{3}, \text { where } \\
& \text { (1) } V_{1} \quad\left\{\quad \left\{v_{i} \in V\left(G_{1} \ominus G_{2}\right): d_{G_{1} \ominus G_{2}}\left(v_{i}\right)=d_{G_{1}}\left(v_{i}\right),\right.\right. \\
&\left.i=1,2, \ldots, n_{1}\right\}, \\
& \text { (2) } V_{2}=\left\{v_{i} \in V\left(G_{1} \ominus G_{2}\right): d_{G_{1} \ominus G_{2}}\left(v_{i}\right)=d_{G_{2}}\left(v_{i}\right)+1,\right. \\
&\left.i=1,2, \ldots, m_{1} n_{2}\right\}, \text { and } \\
& \text { (3) } V_{3}=\left\{v_{i} \in V\left(G_{1} \ominus G_{2}\right): d_{G_{1} \ominus G_{2}}\left(v_{i}\right)=n_{2}+2,\right. \\
&\left.i=1,2, \ldots, m_{1}\right\} .
\end{aligned}
$$

Then, the total irregularity of $G_{1} \ominus G_{2}$ is

$$
\begin{aligned}
& \operatorname{irr}_{t}\left(G_{1} \ominus G_{2}\right)=\sum_{\substack{i=1, j=i+1}}^{\substack{n_{1}+m_{1} n_{2}+m_{1}-1, n_{1}+m_{1} n_{2}+m_{1}}}\left|d_{G_{1} \ominus G_{2}}\left(v_{i}\right)-d_{G_{1} \ominus G_{2}}\left(v_{j}\right)\right| \\
& =\sum_{i=1}^{n_{1}} \sum_{j=i+1}^{n_{1}}\left|d_{G_{1}}\left(v_{i}\right)-d_{G_{1}}\left(v_{j}\right)\right|+ \\
& \sum_{i=1}^{n_{1}} \sum_{j=n_{1}+1}^{n_{1}+m_{1} n_{2}}\left|d_{G_{1}}\left(v_{i}\right)-d_{G_{2}}\left(v_{j}\right)-1\right|+ \\
& \sum_{i=1}^{n_{1}} \sum_{j=n_{1}+m_{1} n_{2}+1}^{n_{1}+m_{1} n_{2}+m 1}\left|d_{G_{1}}\left(v_{i}\right)-n_{2}-2\right|+ \\
& \sum_{i=n_{1}+1}^{n_{1}+m_{1} n_{2}} \sum_{j=i+1}^{n_{1}+m_{1} n_{2}}\left|d_{G_{2}}\left(v_{i}\right)+1-d_{G_{2}}\left(v_{j}\right)-1\right|+ \\
& \sum_{i=n_{1}+1}^{n_{1}+m_{1} n_{2}} \sum_{j=n_{1}+m_{1} n_{2}+1}^{n_{1}+m_{1} n_{2}+m 1}\left|d_{G_{2}}\left(v_{i}\right)+1-n_{2}-2\right| \\
& =\operatorname{irr}_{t}\left(G_{1}\right)+\sum_{i=1}^{n_{1}} \sum_{j=n_{1}+1}^{n_{1}+m_{1} n_{2}}\left|d_{G_{1}}\left(v_{i}\right)-d_{G_{2}}\left(v_{j}\right)-1\right|+m_{1} \\
& \sum_{i=1}^{n_{1}}\left|d_{G_{1}}\left(v_{i}\right)-n_{2}-2\right|+m_{1}^{2} \operatorname{irr}_{t}\left(G_{2}\right)+m_{1}^{2}\left(n_{2}^{2}+n_{2}-2 m_{2}\right) \\
& =\operatorname{irr}_{t}\left(G_{1}\right)+m_{1}^{2} \operatorname{irr}_{t}\left(G_{2}\right)+m_{1}^{2}\left(n_{2}^{2}+n_{2}-2 m_{2}\right)+m_{1} \sum_{i=1}^{n_{1}} \\
& \left|d_{G_{1}}\left(v_{i}\right)-n_{2}-2\right|+\sum_{i=1}^{n_{1}} \sum_{j=n_{1}+1}^{n_{1}+m_{1} n_{2}}\left|d_{G_{1}}\left(v_{i}\right)-d_{G_{2}}\left(v_{j}\right)-1\right| .
\end{aligned}
$$

(III) Also here, one can partition the vertex set of $G_{1} \boxminus G_{2}$ into

(1) $V_{1}=\left\{v_{i} \in V\left(G_{1} \boxminus G_{2}\right): d_{G_{1} \boxminus G_{2}}\left(v_{i}\right)=d_{G_{1}}\left(v_{i}\right)\right.$, $\left.i=1,2, \ldots, n_{1}\right\}$,

(2) $V_{2}=\left\{v_{i} \in V\left(G_{1} \boxminus G_{2}\right): d_{G_{1} \boxminus G_{2}}\left(v_{i}\right)=d_{G_{1}}\left(v_{i}\right)+\right.$ $\left.d_{G_{2}}\left(v_{j}\right), 1 \leq i \leq n_{1}, 1 \leq j \leq n_{2}\right\}$, 
(3) $V_{3}=\left\{v_{i} \in V\left(G_{1} \boxminus G_{2}\right): d_{G_{1} \boxminus G_{2}}\left(v_{i}\right)=2 n_{2}+2\right.$, $\left.i=1,2, \ldots, m_{1}\right\}$.

Then,the total irregularity of $G_{1} \triangleright G_{2}$ is

$$
\begin{aligned}
& \operatorname{irr}_{t}\left(G_{1} \boxminus G_{2}\right)= \\
& \sum_{i=1}^{n_{1}+n_{1} n_{2}+m_{1}-1} \sum_{j=i+1}^{n_{1}+n_{1} n_{2}+m_{1}}\left|d_{G_{1} \boxminus G_{2}}\left(v_{i}\right)-d_{G_{1} \boxminus G_{2}}\left(v_{j}\right)\right| \\
& =\sum_{i=1}^{n_{1}} \sum_{j=i+1}^{n_{1}}\left|d_{G_{1}}\left(v_{i}\right)-d_{G_{1}}\left(v_{j}\right)\right|+ \\
& \sum_{i=1}^{n_{1}} \sum_{j=n_{1}+1}^{n_{1}+n_{1} n_{2}}\left|d_{G_{1}}\left(v_{i}\right)-d_{G_{1} \boxminus G_{2}}\left(v_{j}\right)\right|+ \\
& \sum_{i=1}^{n_{1}} \sum_{j=n_{1}+n_{1} n_{2}+1}^{n_{1}+n_{1} n_{2}+m 1}\left|d_{G_{1}}\left(v_{i}\right)-2 n_{2}-2\right|+ \\
& \sum_{i=n_{1}+1}^{n_{1}+n_{1}} \sum_{j=i+1}^{n_{2}}\left|d_{G_{1} \boxminus G_{2}}\left(v_{i}\right)-d_{G_{1} \boxminus G_{2}}\left(v_{j}\right)\right|+ \\
& \sum_{i=n_{1}+1}^{n_{1}+n_{1} n_{2}} \sum_{j=n_{1}+n_{1} n_{2}+1}^{n_{1}+n_{1} n_{2}+m 1}\left|d_{G_{1} \boxminus G_{2}}\left(v_{i}\right)-2 n_{2}-2\right| .
\end{aligned}
$$

Further, we have

$$
\begin{aligned}
& \sum_{i=1}^{n_{1}} \sum_{j=n_{1}+1}^{n_{1}+n_{1} n_{2}}\left|d_{G_{1} \boxminus G_{2}}\left(v_{j}\right)-d_{G_{1}}\left(v_{i}\right)\right| \\
& =\sum_{i=1}^{n_{1}} \sum_{k=1}^{n_{1}} \sum_{t=1}^{n_{2}}\left|d_{G_{1}}\left(v_{k}\right)+d_{G_{2}}\left(v_{t}\right)-d_{G_{1}}\left(v_{i}\right)\right| \\
& \leq \sum_{i=1}^{n_{1}} \sum_{k=1}^{n_{1}} \sum_{t=1}^{n_{2}}\left(\left|d_{G_{1}}\left(v_{k}\right)-d_{G_{1}}\left(v_{i}\right)\right|+d_{G_{2}}\left(v_{t}\right)\right) \\
& =n_{2} \operatorname{irr}_{t}\left(G_{1}\right)+2 n_{1}^{2} m_{2},
\end{aligned}
$$

$$
\begin{aligned}
& \sum_{s=n_{1}+1}^{n_{1}+n_{1} n_{2}} \sum_{t=s+1}^{n_{1}+n_{1} n_{2}}\left|d_{G_{1} \boxminus G_{2}}\left(v_{s}\right)-d_{G_{1} \boxminus G_{2}}\left(v_{t}\right)\right| \\
& =\sum_{i, j=1}^{n_{1}, n_{2}} \sum_{k, l=1}^{n_{1}, n_{2}}\left|d_{G_{1}}\left(v_{i}\right)+d_{G_{2}}\left(v_{j}\right)-d_{G_{1}}\left(v_{k}\right)-d_{G_{2}}\left(v_{l}\right)\right| \\
& \leq \sum_{i, j=1}^{n_{1}, n_{2}} \sum_{k, l=1}^{n_{1}, n_{2}}\left(\left|d_{G_{1}}\left(v_{i}\right)-d_{G_{1}}\left(v_{k}\right)\right|+\left|d_{G_{2}}\left(v_{j}\right)-d_{G_{2}}\left(v_{l}\right)\right|\right) \\
& =n_{2}^{2} \operatorname{irr}_{t}\left(G_{1}\right)+n_{1}^{2} \operatorname{irr}_{t}\left(G_{2}\right) \\
& \quad \sum_{i=1}^{n_{1}} \sum_{j=n_{1}+n_{1} n_{2}+1}^{n_{1}+n_{1} n_{2}+m 1}\left|d_{G_{1}}\left(v_{i}\right)-2 n_{2}-2\right|= \\
& m_{1} \sum_{i=1}^{n_{1}}\left|d_{G_{1}}\left(v_{i}\right)-2 n_{2}-2\right|, \quad \text { and }
\end{aligned}
$$$$
\sum_{i=n_{1}+1}^{n_{1}+n_{1} n_{2}} \sum_{j=n_{1}+n_{1} n_{2}+1}^{n_{1}+n_{1} n_{2}+m 1}\left|d_{G_{1} \boxminus G_{2}}\left(v_{i}\right)-2 n_{2}-2\right|=
$$$$
m_{1} \sum_{k=1}^{n_{1}} \sum_{l=1}^{n_{2}}\left|d_{G_{1}}\left(v_{k}\right)+d_{G_{2}}\left(v_{l}\right)-2 n_{2}-2\right| .
$$

From (7), 8, ,9), (10) and (11), we obtain

$$
\begin{aligned}
& \operatorname{irr}_{t}\left(G_{1} \boxminus G_{2}\right) \leq\left(n_{2}^{2}+n_{2}+1\right) \operatorname{irr}_{t}\left(G_{1}\right)+ \\
& n_{1}^{2} \operatorname{irr}_{t}\left(G_{2}\right)+2 n_{1}^{2} m_{2}+m_{1} \sum_{i=1}^{n_{1}}\left|d_{G_{1}}\left(v_{i}\right)-2 n_{2}-2\right|+ \\
& \sum_{i=1}^{n_{1}} \sum_{l=1}^{n_{2}}\left|d_{G_{1}}\left(v_{i}\right)+d_{G_{2}}\left(v_{l}\right)-2 n_{2}-2\right| .
\end{aligned}
$$

$(I V)$ Here again, we partition $V\left(G_{1} \boxminus G_{2}\right)$ into three subsets

(1) $V_{1}=\left\{v_{i} \in V\left(G_{1} \boxminus G_{2}\right): d_{G_{1} \boxminus G_{2}}\left(v_{i}\right)=\left(n_{2}+1\right) d_{G_{1}}\left(v_{i}\right)\right.$, $\left.i=1,2, \ldots, n_{1}\right\}$

(2) $V_{2}=\left\{v_{i} \in V\left(G_{1} \boxminus G_{2}\right): d_{G_{1} \boxminus G_{2}}\left(v_{i}\right)=d_{G_{2}}\left(v_{i}\right)+2\right.$ $\left.i=1,2, \ldots, m_{1} n_{2}\right\}$,

(3) $V_{3}=\left\{v_{i} \in V\left(G_{1} \boxminus G_{2}\right): d_{G_{1} \boxminus G_{2}}\left(v_{i}\right)=2\right.$, $\left.i=1,2, \ldots, m_{1}\right\}$,

and then, the total irregularity of $G_{1} \boxminus G_{2}$ is

$$
\begin{aligned}
& \operatorname{irr}_{t}\left(G_{1} \boxminus G_{2}\right)= \sum_{i=1}^{n_{1}+m_{1} n_{2}+m_{1}-1} \sum_{j=i+1}^{n_{1}+m_{1} n_{2}+m_{1}}\left|d_{G_{1} \boxminus G_{2}}\left(v_{i}\right)-d_{G_{1} \boxminus G_{2}}\left(v_{j}\right)\right| \\
&= \sum_{i=1}^{n_{1}} \sum_{j=i+1}^{n_{1}}\left|\left(n_{2}+1\right) d_{G_{1}}\left(v_{i}\right)-\left(n_{2}+1\right) d_{G_{1}}\left(v_{j}\right)\right|+ \\
& \sum_{i=1}^{n_{1}} \sum_{j=n_{1}+1}^{n_{1}+m_{1} n_{2}}\left|\left(n_{2}+1\right) d_{G_{1}}\left(v_{i}\right)-d_{G_{2}}\left(v_{j}\right)-2\right|+ \\
& \sum_{i=1}^{n_{1}} \sum_{j=n_{1}+m_{1} n_{2}+1}^{n_{1}+m_{1} n_{2}+m 1}\left|\left(n_{2}+1\right) d_{G_{1}}\left(v_{i}\right)-2\right|+ \\
& \sum_{i=n_{1}+1}^{n_{1}+m_{1} n_{2}} \sum_{j=i+1}^{n_{1}+m_{1} n_{2}}\left|d_{G_{2}}\left(v_{i}\right)+2-d_{G_{2}}\left(v_{j}\right)-2\right|+ \\
& \sum_{i=n_{1}+1}^{n_{1}+m_{1} n_{2}} \sum_{j=n_{1}+m_{1} n_{2}+m 1}^{n_{1}+n_{2}+1}\left|d_{G_{2}}\left(v_{i}\right)+2-2\right| \\
&=\left(n_{2}+1\right) \operatorname{irr}_{t}\left(G_{1}\right)+ \\
& \sum_{i=1}^{n_{1}}\left(m_{1} n_{2}\left(\left(n_{2}+1\right) d_{G_{1}}\left(v_{i}\right)-2\right)-2 m_{1} m_{2}\right)+ \\
& \sum_{i=1}^{n_{1}} m_{1} m_{1}\left(\left(n_{2}+1\right) d_{G_{1}}\left(v_{i}\right)-2\right)+m_{1}^{2} \operatorname{irr}_{t}\left(G_{2}\right)+2 m_{1}^{2} m_{2} \\
& 2 m_{1}^{2}\left(n_{2}^{2}+2 n_{2}+m_{2}+G_{1}\right)+m_{1}^{2} \operatorname{irr}_{t}\left(G_{2}\right)+ \\
& n_{2}+2 n_{1} m_{1}\left(n_{2}+m_{2}+1\right) .
\end{aligned}
$$

The following results are direct consequences of Theorem 19

COROllary 5.1. Let $C_{n}$ be a cycle on $n$ vertices, $P_{n}$ be a path on $n$ vertices and $G$ be a simple graph with $p=|V(G)|$ vertices and $q=|E(G)|$ edges. Then

(1) $\operatorname{irr}_{t}\left(C_{n} \odot G\right)=n^{2} \operatorname{irr}_{t}(G)+n^{2} p(p+1)$

(2) $\operatorname{irr}_{t}\left(G \odot C_{n}\right)=\operatorname{irr}_{t}(G)+n(n-3) p^{2}+2(2 n-1) p q+2 q^{2}$

(3) $\operatorname{irr}_{t}\left(P_{n} \odot G\right)=n^{2} \operatorname{irr}_{t}(G)+n^{2} p^{2}+n(n-2) p-2 n q-2$

(4) $\operatorname{irr}_{t}\left(G \odot P_{n}\right)=\operatorname{irr}_{t}(G)+(n-2)(n+1) p^{2}+4(n-1) p q+2 q^{2}$ 
Corollary 5.2. Let $C_{n}$ be a cycle on $n$ vertices, $P_{n}$ be a path on $n$ vertices and $G$ be a simple graph with $p=|V(G)|$ vertices and $q=|E(G)|$ edges. Then

(1) $\operatorname{irr}_{t}\left(C_{n} \boxminus G\right)=n^{2} \operatorname{irr}_{t}(G)+2 n^{2} p(p+1)$

(2) $\operatorname{irr}_{t}\left(G \boxminus C_{n}\right)=(n+1) \operatorname{irr}_{t}(G)+2\left(n^{2}+3 n+1\right) q^{2}-$ $2(2 n+1) p q$

(3) $\operatorname{irr}_{t}\left(P_{n} \boxminus G\right)=(n-1)^{2} \operatorname{irr}_{t}(G)+2(n-1)^{2} p^{2}+$ $2 n(n-2) p-2(n-1) q-2$

(4) $\operatorname{irr}_{t}\left(G \boxminus P_{n}\right)=(n+1) \operatorname{irr}_{t}(G)+2\left(n^{2}+4 n-2\right) q^{2}-4 n p q$.

\section{TOTAL IRREGULARITY OF HIERARCHICAL} PRODUCT GRAPHS

The hierarchical product of graphs, introduced in [6], is defined as follows. Let $G_{i}=\left(V_{i}, E_{i}\right)$ be graphs with vertex sets $V_{i}, i=1,2$, having a distinguished or root vertex, labeled 0 . The hierarchical product $G_{1} \sqcap G_{2}$ is the graph with vertices $x_{1} x_{2}, x_{i} \in V_{i}$, and edges $\left\{x_{1} x_{2}, y_{1} y_{2}\right\}$ where either $x_{1}=y_{1}$ and $x_{2} \sim y_{2}$ in $G_{2}$, or $x_{2}=0$ and $x_{1} \sim y_{1}$ in $G_{1}$. Thus, $G_{1} \sqcap G_{2}$ has $\left|V_{1}\right|\left|V_{2}\right|$ vertices and $\left|E_{1}\right|+\left|V_{1}\right|\left|E_{2}\right|$ edges and $d_{G_{1} \sqcap G_{2}}\left(x_{1} x_{2}\right)=d_{G_{1}}\left(x_{1}\right)+d_{G_{2}}\left(x_{2}\right)$ if $x_{2}=0$ otherwise, $d_{G_{1} \sqcap G_{2}}\left(x_{1} x_{2}\right)=d_{G_{2}}\left(x_{2}\right)$.

THEOREM 20. Let $G_{i}=\left(V_{i}, E_{i}\right), i=1,2$ be graphs with $\left|V_{1}\right|=n_{1},\left|V_{2}\right|=n_{2},\left|E_{1}\right|=m_{1}$ and $\left|E_{2}\right|=m_{2}$. The total irregularity of the hierarchical product $G_{1} \sqcap G_{2}$ is

$\operatorname{irr}_{t}\left(G_{1} \sqcap G_{2}\right) \leq \operatorname{irr}_{t}\left(G_{1}\right)+2 n_{1} n_{2} m_{1}+n_{1}^{2} \operatorname{irr}_{t}\left(G_{2}\right)$.

Proof. Let $v_{1} \in V\left(G_{2}\right)$ be the root of $G_{2}$ and the degree sequences of $G_{1}, G_{2}$ are:

$\mathrm{D}\left(\mathrm{G}_{1}\right)=\left[d_{G_{1}}\left(u_{1}\right), d_{G_{1}}\left(u_{2}\right), \cdots, d_{G_{1}}\left(u_{n_{1}-1}\right), d_{G_{1}}\left(u_{n_{1}}\right)\right]$,

$\mathrm{D}\left(\mathrm{G}_{2}\right)=\left[d_{G_{2}}\left(v_{1}\right), d_{G_{2}}\left(v_{2}\right), \cdots, d_{G_{2}}\left(v_{n_{2}-1}\right), d_{G_{2}}\left(v_{n_{2}}\right)\right]$.

By the definition of hierarchical product graphs, the degree sequence of $G_{1} \sqcap G_{2}$ is

$$
\begin{aligned}
\mathrm{D}\left(\mathrm{G}_{1} \sqcap \mathrm{G}_{2}\right)= & {\left[d_{G_{2}}\left(v_{1}\right)+d_{G_{1}}\left(u_{1}\right), d_{G_{2}}\left(v_{1}\right)+d_{G_{1}}\left(u_{2}\right), \cdots,\right.} \\
& d_{G_{2}}\left(v_{1}\right)+d_{G_{1}}\left(u_{n_{1}-1}\right), d_{G_{2}}\left(v_{1}\right)+d_{G_{1}}\left(u_{n_{1}}\right), \\
& \left.d_{G_{2}}^{n_{1}}\left(v_{2}\right), d_{G_{2}}^{n_{1}}\left(v_{3}\right), \cdots, d_{G_{2}}^{n_{1}}\left(v_{n_{2}-1}\right), d_{G_{2}}^{n_{1}}\left(v_{n_{2}}\right)\right] .
\end{aligned}
$$

Hence, the total irregularity of $G_{1} \sqcap G_{2}$ is

$$
\begin{aligned}
\operatorname{irr}_{t}\left(G_{1} \sqcap G_{2}\right)= & \frac{1}{2} \sum_{u_{i} v_{i}, u_{j} v_{j} \in V\left(G_{1} \sqcap G_{2}\right)}\left|d_{G_{1} \sqcap G_{2}}\left(u_{i} v_{i}\right)-d_{G_{1} \sqcap G_{2}}\left(u_{j} v_{j}\right)\right| \\
= & \frac{1}{2} \sum_{u_{i}, u_{j} \in V\left(G_{1}\right), v_{1} \in V\left(G_{2}\right)} \mid\left(d_{G_{2}}\left(v_{1}\right)+d_{G_{1}}\left(u_{i}\right)\right)- \\
& \left(d_{G_{2}}\left(v_{1}\right)+d_{G_{1}}\left(u_{j}\right)\right) \mid+\frac{n_{1}}{2} \\
& \sum_{u_{i} \in V\left(G_{1}\right), v_{1}, v_{j} \in V\left(G_{2}\right)}\left|d_{G_{2}}\left(v_{1}\right)+d_{G_{1}}\left(u_{i}\right)-d_{G_{2}}\left(v_{j}\right)\right| \\
& +\frac{n_{1}^{2}}{2} \sum_{v_{i}, v_{j} \in V\left(G_{2}\right), v_{i} \neq v_{1}, v_{j} \neq v_{1}}\left|d_{G_{2}}\left(v_{i}\right)-d_{G_{2}}\left(v_{j}\right)\right| \\
\leq & \sum_{\operatorname{rr}_{t}\left(G_{1}\right)+\frac{n_{1}}{2} 2} \sum_{u_{i} \in V\left(G_{1}\right), v_{1}, v_{j} \in V\left(G_{2}\right)} d_{G_{1}}\left(u_{i}\right)+ \\
& \frac{n_{1}}{2} \sum_{u_{i} \in V\left(G_{1}\right), v_{1}, v_{j} \in V\left(G_{2}\right)}\left|d_{G_{2}}\left(v_{1}\right)-d_{G_{2}}\left(v_{j}\right)\right|+
\end{aligned}
$$

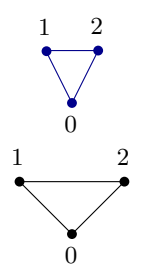

(a)

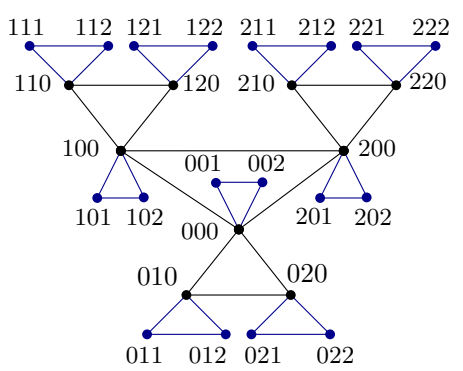

(c)

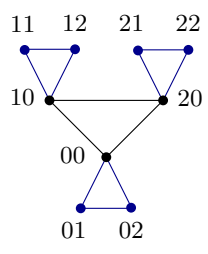

(b)

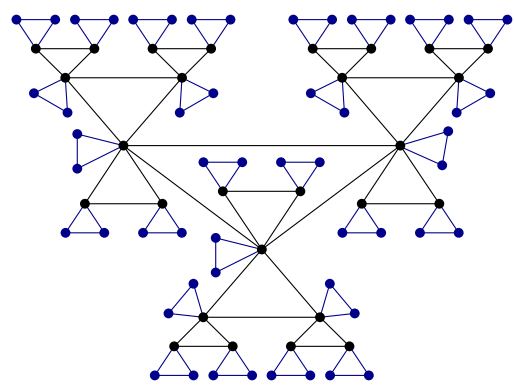

(d)

Fig. 3. Hierarchical product of graphs $(a) K_{3}$, (b) $K_{3}^{2}=K_{3} \sqcap K_{3}$, (c) $K_{3}^{3}=K_{3}^{2} \sqcap K_{3}$ and $(d) K_{3}^{4}=K_{3}^{3} \sqcap K_{3}$.

$$
\begin{aligned}
& \frac{n_{1}^{2}}{2} \sum_{v_{i}, v_{j} \in V\left(G_{2}\right)}\left|d_{G_{2}}\left(v_{i}\right)-d_{G_{2}}\left(v_{j}\right)\right|- \\
& \left.\frac{n_{1}^{2}}{2} \sum_{v_{1}, v_{j} \in V\left(G_{2}\right)}\left|d_{G_{2}}\left(v_{1}\right)-d_{G_{2}}\left(v_{j}\right)\right|\right) \\
= & \operatorname{irr}_{t}\left(G_{1}\right)+n_{1}\left(2 n_{2} m_{1}\right)+ \\
& \frac{n_{1}^{2}}{2} \sum_{v_{1}, v_{j} \in V\left(G_{2}\right)}\left|d_{G_{2}}\left(v_{1}\right)-d_{G_{2}}\left(v_{j}\right)\right|+ \\
& \left.n_{1}^{2} \operatorname{irr}_{t}\left(G_{2}\right)-\frac{n_{1}^{2}}{2} \sum_{v_{1}, v_{j} \in V\left(G_{2}\right)}\left|d_{G_{2}}\left(v_{1}\right)-d_{G_{2}}\left(v_{j}\right)\right|\right) \\
= & \operatorname{irr}_{t}\left(G_{1}\right)+2 n_{1} n_{2} m_{1}+n_{1}^{2} \operatorname{irr}_{t}\left(G_{2}\right) .
\end{aligned}
$$

The total irregularity of $K_{n}^{r}=K_{n}^{r-1} \sqcap K_{n}$ for $r \geq 1$ is given in Proposition 2 The hierarchical products $K_{3}^{2}, K_{3}^{3}, K_{3}^{4}$ are illustrated in Figure 3

PROPOSITION 2. The total irregularity of the hierarchical product $K_{n}^{r}$ is

$$
\operatorname{irr}_{t}\left(K_{n}^{r}\right)=\frac{n^{2}\left(n^{r}-1\right)\left(n^{r-1}-1\right)}{n+1}
$$

Proof. The degree sequences of the hierarchical products $K_{n}^{1}, \cdots, K_{n}^{4}$ according to the definition of the hierarchical product are

$$
\begin{aligned}
& \mathrm{D}\left(\mathrm{K}_{\mathrm{n}}^{1}\right)=\left[(n-1)^{n}\right], \\
& \mathrm{D}\left(\mathrm{K}_{\mathrm{n}}^{2}\right)=\left[(2(n-1))^{n},(n-1)^{n(n-1)}\right], \\
& \mathrm{D}\left(\mathrm{K}_{\mathrm{n}}^{3}\right)=\left[(3(n-1))^{n},(2(n-1))^{n(n-1)},(n-1)^{n^{2}(n-1)}\right],
\end{aligned}
$$




$$
\begin{aligned}
\mathrm{D}\left(\mathrm{K}_{\mathrm{n}}^{4}\right)= & {\left[(4(n-1))^{n},(3(n-1))^{n(n-1)},(2(n-1))^{n^{2}(n-1)},\right.} \\
& \left.(n-1)^{n^{3}(n-1)}\right] .
\end{aligned}
$$

The degree sequence of the hierarchical products $K_{n}^{r}$ for positive integer $r$ is

$$
\begin{aligned}
\mathrm{D}\left(\mathrm{K}_{\mathrm{n}}^{\mathrm{r}}\right)= & {\left[(r(n-1))^{n},((r-1)(n-1))^{(n-1) n},\right.} \\
& ((r-2)(n-1))^{(n-1) n^{2}},((r-3)(n-1))^{(n-1) n^{3}}, \\
& \cdots,(3(n-1))^{(n-1) n^{(r-3)}},(2(n-1))^{(n-1) n^{(r-2)},} \\
& \left.(n-1)^{(n-1) n^{(r-1)}}\right] .
\end{aligned}
$$

Then

$$
\begin{gathered}
\operatorname{irr}_{t}\left(K_{n}^{r}\right)=n(n-1)^{2}\left(n+2 n^{2}+3 n^{3}+\cdots+(r-3) n^{r-3}+\right. \\
\left.(r-2) n^{r-2}+(r-1) n^{r-1}\right)+n^{2}(n-1)^{3}(n+ \\
2 n^{2}+3 n^{3}+\cdots+(r-4) n^{r-4}+(r-3) n^{r-3}+ \\
\left.(r-2) n^{r-2}\right)+n^{4}(n-1)^{3}\left(n+2 n^{2}+3 n^{3}+\right. \\
\left.\cdots+(r-5) n^{r-5}+(r-4) n^{r-4}+(r-3) n^{r-3}\right)+ \\
\cdots+n^{2 r-6}(n-1)^{3}\left(n+2 n^{2}\right)+n^{2 r-4}(n-1)^{3} n \\
=n(n-1)^{2} \sum_{i=1}^{r-1} i n^{i}+(n-1)^{3}\left(n^{2} \sum_{i=1}^{r-2} i n^{i}+\right. \\
\left.n^{4} \sum_{i=1}^{r-3} i n^{i}+\cdots+n^{2(r-2)} \sum_{i=1}^{r-(r-1)} i n^{i}\right) \\
=n(n-1)^{2} \sum_{i=1}^{r-1} i n^{i}+(n-1)^{3} \sum_{j=1}^{r-2}\left(n^{2 j} \sum_{i=1}^{r-(j+1)} i n^{i}\right) \\
=n\left(n+(r-1) n^{r+1}-r n^{r}\right)+ \\
\frac{n\left(n^{2 r}-n^{2}+(r-1) n^{r}-(r-1) n^{r+2}\right)}{n+1} \\
=\frac{n^{2}\left(n^{r}-1\right)\left(n^{r-1}-1\right)}{n+1} .
\end{gathered}
$$

\section{CONCLUSION}

The results presented in this paper complement the results from [3]. Here we consider the total irregularity of simple undirected graphs under several graph operations. We presented the exact expression of the total irregularity of subdivision graph, triangle parallel graph, superposition graph, total graph, double graph, extended double graph, subdivision-vertex corona, subdivision-edge corona and subdivision-edge neighbourhood corona and sharp upper bounds of the total irregularity of thorn graph, subdivision-vertex neighbourhood corona and the hierarchical product of graphs. It is an open problem if the presented upper bounds on the total irregularity of thorn graph, subdivision-vertex neighbourhood corona and the hierarchical product of graphs are the best possible.

\section{REFERENCES}

[1] H. Abdo, S. Brandt, and D. Dimitrov. The total irregularity of a graph. Discrete Math. Theor. Comput. Sci., 16:201-206, 2014.
[2] H. Abdo and D. Dimitrov. The irregularity of graphs under graph operations. Discuss. Math. Graph Theory, 34:263-278, 2014.

[3] H. Abdo and D. Dimitrov. The total irregularity of graphs under graph operations. Miskolc Math. Notes, 15:3-17, 2014.

[4] M. Albertson. The irregularity of a graph. Ars Comb., 46.

[5] N. Alon. Eigenvalues and expanders. Combinatorica, 6:8396, 1986.

[6] L. Barriére, F. Comellas, C. Dalfó, and M. Fiol. The hierarchical product of graphs. Discrete Appl. Math., 157:36-48, 2009.

[7] F. Bell. A note on the irregularity of graphs. Linear Algebra Appl., 161:45-54, 1992.

[8] D. Bonchev and D. Klein. On the wiener number of thorn trees, stars, rings, and rods. Croat. Chem. Acta, 75:613-620, 2002.

[9] N. De. Augmented eccentric connectivity index of some thorn graphs. Intern. J. Appl. Math. Res., 1:671-680, 2012.

[10] N. De. On eccentric connectivity index and polynomial of thorn graph. Appl. Math., 3:931-934, 2012.

[11] N. De, A. Pal, and S. Nayeem. Modified eccentric connectivity of generalized thorn graphs. Intern J. Computational Math., 2014. http://dx.doi.org/10.1155/2014/436140.

[12] T. Dehghan-Zadeh, H. Hua, A. Ashrafi, and N. Habibi. Remarks on a conjecture about randić index and graph radius. Miskolc Math. Notes, 14:845-850, 2013.

[13] D. Dimitrov and R. Škrekovski. Comparing the irregularity and the total irregularity of graphs. Ars Math. Contemp, 9:4550,2015

[14] I. Gutman. Distance in thorny graph. Publ. Inst. Math., 63:3136, 1998.

[15] P. Hansen and H. Mélot. Variable neighborhood search for extremal graphs 9. bounding the irregularity of a graph. $D I$ MACS Ser. Discrete Math. Theoret. Comput. Sci., 69:253264, 1962.

[16] A. Heydari and I. Gutman. On the terminal wiener index of thorn graphs. Kragujevac J. Science, 32:57-64, 2010.

[17] H. Hua, S. Zhang, and K. Xu. Further results on the eccentric distance sum. Discrete Appl. Math., 160.

[18] K. Kathiresan and C. Parameswaran. Certain generalized thorn graphs and their wiener indices. J. Appl. Math. Informatics, 30:793-807, 2012.

[19] X. Liu and P. Lub. Spectra of subdivision-vertex and subdivision-edge neighbourhood corona. Linear Algebra Appl., 438:3547-3559, 2013.

[20] P. Lu and Y. Miao. Spectra of the subdivision-vertex and subdivision-edge corona. arXiv:1302.0457v2.

[21] H. Walikar, H. Ramane, L. Sindagi, S. Shirakol, and I. Gutman. Hosoya polynomial of thorn trees, rods, rings, and stars. Kragujevac J. Science, 28:47-56, 2006.

[22] B. Zhou. On modified wiener indices of thorn trees. Kragujevac J. Math., 27:5-9, 2005.

[23] B. Zhou and D. Vukičevič. On wiener-type polynomials of thorn graphs. J. Chemometrics, 23:600-604, 2009. 